\title{
The Importance of William M. Magruder
}

LESS than a year ago, even Mr William M. Magruder's fondest admirers, of whom there are many, must have been downcast at the collapse of his campaign to persuade Congress to sponsor the supersonic transport aircraft project. Even at the time, it seemed as if a more subtle person might have been more successful. Mr Magruder has a reputation as a salesman of new ideas, but he is a high pressure salesman-the kind of man who tends to begin his sales pitch by jamming his foot in the door. It is no wonder that Congress's unwillingness to stomach the SST was if anything strengthened by the sense which $\mathrm{Mr}$ Magruder gave a great many senators that there were no options open to them. In retrospect, it is of course extremely strange that such an experienced operator as $\mathrm{Mr}$ Magruder should have failed to anticipate the consequences of a refusal by Congress to vote the money for which he asked. Yet, to the Administration's chagrin, there appear to have been no contingency plans. Lesser men than $\mathrm{Mr}$ Magruder would no doubt have quickly found themselves banished to the outermost regions of the United States. It is therefore something of a surprise that Mr Magruder has now emerged as the head of what is called the New Technological Opportunities Program, a still somewhat amorphous scheme for winning public benefits of various kinds from the opportunities which technology now provides.

Quite apart from the question whether Mr Magruder is the right man for such an intricate job, the decision to set up a White House organization for the exploitation of technology raises all kinds of difficult problems, both in the management of the United States government's interests in science and technology and in the process of forming an accurate appreciation of what science and technology may do for a society such as that of the United States. The most obvious line of speculation since $\mathrm{Mr}$ Magruder's new job became known is the extent to which disappointment will cut across the operations of the Office of Science and Technology, hitherto the principal channel for the coordination of the federal government's activities in the support of basic science and in some fields of technology as well. From Dr Edward David down, the air has been thick with loyal protestations that the new arrangements imply no diminution of authority for the Office of Science and Technology and some have even said that there will be benefits in having Mr Magruder at the White House to lend support to projects which seem to have a technological flavour of some kind. Unfortunately, however, the situation is a good deal more complicated than that. In the past few years, the Office of Science and Technology has done a great deal to strengthen the representation of agencies such as the National Science Foundation in the annual competition for budget appropriations.

The biggest danger now is that Mr Magruder, busy as a bee as is his habit, will muddy the waters unnecessarily. Even in the United States, there are serious limitations to the uses which can be made of technology. People say, quite rightly, that the threat of another earthquake in San Francisco is sombre, that the prospect of hurricanes each autumn is an affront against human dignity and that it should somehow be possible to get rid of the constant embarrassment about the balance of payments by wringing a little more blood out of the stone of technology. The trouble, alas, is that there is no easy way of knowing precisely when it is possible by means of a strictly technological development to make wishes into realities. The objection to much of what has in the past few years been said of the power of technology to cure social ills of various kinds is that the wish has been the father of the thought. The truth is, of course, that even when it is acknowledged that cancer, for example, would be best got rid of, or when society as a whole yearns for the removal of earthquakes, there is a limit to the amount of money which can be usefully spent in the attainment of these desirable objectives. The danger now is that Mr Magruder's brash new broom will be sweeping away energetically for a good time before this simple lesson has been re-learned. The result will be, if the worst fears are fulfilled, that the cause of rationality in the applications of technology to practical problems will have been set back by several years. Will Mr Magruder be more perceptive in his handling of this question than in his dealing with the supersonic transport?

\section{Years Ago}

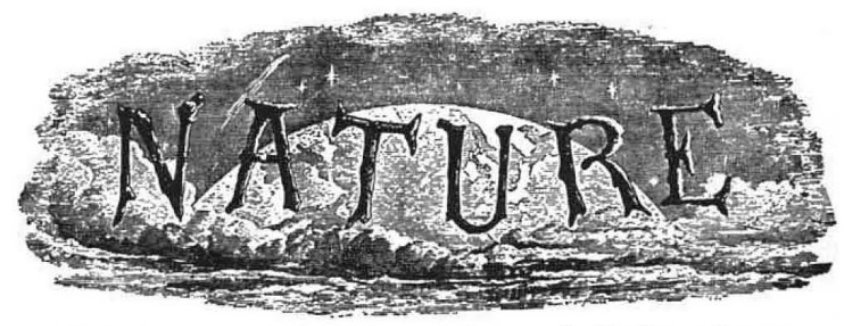

But the most interesting, perhaps, of all the subjects with which the Academie des Sciences busied itself, was that of seeking an economical means of alimeniation for the inhabitants of Paris during the siege. Given certain limited sources of supply, a fixed amount of suitable organic matter, and the problem was how to use the same to the fullest and most profitable degree. Of sheep and oxen there was but an exceedingly limited provision in proportion to the very populous state of the city, and although corn and wine were said to be in abundance, there is no doubt the authorities were from the first sorely troubled by the vague estimates that were published of these comestibles.

A proposition to manufacture artificial milk, brought forward by M. Gaudin, seems worthy of some notice. That gentleman estimated that 500,000 litres per day of milk could be prepared in Paris at an exceedingly trifling cost, which should have all the nutritious qualities of good milk, and which should, besides, be neither unpleasant of taste or smell. An emulsion at a very high temperature is made of bouillon de viande prepared from bones, fat, and gelatine, and when cold, a product is obtained resembling in taste stale milk of a cheesy flavour; the components of ordinary milk are all present, the gelatine representing the casein ; fat, the butter ; and sugar, the sugar of milk. For admixture with coffee, chocolate, soup, \&c., the milk is said to be by no means disagreeable.

Many propositions were brought forward to economise the blood from the abattoir, the plan suggested by $M$. Gaultier of mixing it with flour in the manufacture of bread being perhaps the best and simplest, as the fibrine and albumen, so rich in nitrogen-of which the alimentary properties are well known-are in this way utilised to the highest degree. Less inviting is the proposal of M. Fud to consume he carcases of animals that died of typhus, rhinderpest, and other diseases, the flesh in these instances being, so asserts M. Fud, capable of use as food, if only cooked in a suitable manner.

From Nature, 5, 45, November 16, 1871 